\title{
Therapeutic effects of protein kinase N3 small interfering RNA and doxorubicin combination therapy on liver and lung metastases
}

\author{
YOSHIYUKI HATTORI $^{1}$, TAKUTO KIKUCHI ${ }^{1}$, MARI NAKAMURA ${ }^{1}$, KEI-ICHI OZAKI $^{2}$ and HIRAKU ONISHI \\ ${ }^{1}$ Department of Drug Delivery Research, Hoshi University, Tokyo 142-8501; ${ }^{2}$ Education and Research Center for \\ Fundamental Pharmaceutical Sciences, Osaka University of Pharmaceutical Sciences, Takatsuki, Osaka 569-1094, Japan
}

Received April 9, 2016; Accepted March 14, 2017

DOI: $10.3892 / 01.2017 .6830$

\begin{abstract}
It has been reported that suppression of protein kinase N3 (PKN3) expression in vascular and lymphatic endothelial cells results in the inhibition of tumor progression and lymph node metastasis formation. The present study investigated whether combination therapy of small interfering RNA (siRNA) against PKN3 and doxorubicin (DXR) could increase therapeutic efficacy against liver and lung metastases. In vitro transfection of $\mathrm{PKN} 3$ siRNA into $\mathrm{PKN} 3$-positive MDA-MB-231, LLC, and Colon 26 cells and PKN3-negative MCF-7 cells did not inhibit cell growth and did not increase sensitivity to DXR. However, following in vivo treatment, PKN3 siRNA suppressed the growth of liver MDA-MB-231 and lung LLC and MCF-7 metastases, although combination therapy with DXR did not increase the therapeutic efficacy. By contrast, in liver MCF-7 metastases, PKN3 siRNA or DXR alone did not exhibit significant inhibition of tumor growth, but their combination significantly improved therapeutic efficacy. Treatment of liver MDA-MB-231 metastases with PKN3 siRNA induced a change in vasculature structure via suppression of PKN3 mRNA expression. PKN3 siRNA may induce antitumor effects in lung and liver metastases by suppression of PKN3 expression in stroma cells, such as endothelial cells. From these findings, PKN3 siRNA alone or in combination with DXR may reduce the tumor growth of liver and lung metastases regardless of PKN3 expression in tumor cells.
\end{abstract}

\section{Introduction}

Metastasis is the most lethal aspect of cancer, due to the challenges in treating the metastasis and spread of cancer to key organs, including the lung, liver and brain. Consequently, metastasis remains a major challenge for the clinical

Correspondence to: Dr Yoshiyuki Hattori, Department of Drug Delivery Research, Hoshi University, 2-4-41 Ebara, Shinagawa, Tokyo 142-8501, Japan

E-mail: yhattori@hoshi.ac.jp

Key words: protein kinase N3, siRNA, doxorubicin, liver metastasis, lung metastasis management and prognosis of patients with cancer. Therefore, novel systemic therapies for tumor metastasis are required. RNA interference can be used as a novel therapeutic modality for metastasis through specific silencing of therapeutically relevant genes in vivo (1-3). Synthetic small interfering RNAs (siRNAs), which are small, double-stranded RNAs, are substrates for the RNA-induced silencing complex. However, there are challenges associated with the in vivo delivery of siRNA, such as enzymatic instability and low cellular uptake (1).

Protein kinase N3 (PKN3) has been identified as a downstream effector of the phosphoinositide-3-kinase signaling pathway (4). Loss of PKN3 function in vascular and lymphatic endothelial cells results in the inhibition of tumor progression and lymph node metastasis (5), although the molecular mechanism by which PKN3 contributes to malignant growth and tumorigenesis is not well understood. Gene silencing of PKN3 expression by liposomal PKN3 siRNA (Atu027) inhibited tumor growth and metastasis formation by modulating tumor-associated angiogenesis in various cancer mouse models $(5,6)$. Atu027 is currently being tested in a Phase I clinical trial in cancer therapy (7). Therefore, PKN3 is considered a promising therapeutic target for metastasis.

For in vitro and in vivo gene delivery, cationic liposomes composed 1,2-dioleoyl-3-trimethylammonium-propane methyl sulfate salt (DOTAP)/cholesterol (Chol) or DOTAP/1,2-dioleoyl-sn-glycero-3-phosphoethanolamine (DOPE) have often been used (8-10). Systemic injection of a cationic liposome/siRNA complex (lipoplex) can efficiently deliver siRNA to the lungs (11). Electrostatic interactions between positively charged lipoplexes and negatively charged erythrocytes cause agglutination (12), and the agglutinates contribute to high entrapment of lipoplexes in the highly extended lung capillaries (13). Previously, it was reported that intravenous injection of DOTAP/DOPE lipoplexes could deliver siRNA into lung metastasis and suppress the expression of a target gene (11). Furthermore, it was demonstrated that intravenous sequential injection of chondroitin sulfate plus DOTAP/Chol lipoplex into mice with liver metastasis could deliver siRNA efficiently to the metastasis without accumulation in the lungs, and suppress expression of a target gene in tumor cells $(14,15)$. Therefore, in the present study, the therapeutic efficacy of treatment with PKN3 siRNA was evaluated using the aforementioned transfection methods against liver 
and lung metastases. Furthermore, it was examined whether a combination of PKN3 siRNA and doxorubicin (DXR) could increase therapeutic efficacy against metastases.

\section{Materials and methods}

Materials. DOTAP was obtained from Avanti Polar Lipids Inc. (Alabaster, AL, USA). Chol and chondroitin sulfate C sodium salt were purchased from Wako Pure Chemical Industries, Ltd. (Osaka, Japan). DOPE was obtained from NOF Corporation (Tokyo, Japan). DXR was purchased from Wako Pure Chemical Industries Inc.

siRNA. Mouse/human specific PKN3 siRNA and pGL2-luciferase siRNA (Cont siRNA), as a negative control for PKN3 siRNA (blunt-ended 23-mer, alternating 2'-O-methyl modified), was synthesized by Sigma-Aldrich (Merck KGaA, Darmstadt, Germany). The siRNA sequences of the PKN3 siRNA were as follows: Sense, 5'-AgAcUuGaGgAcUuCcUg GaCaA-3' and antisense, 5'-uUgUcCaGgAaGuCcUcAaGu Cu-3' (5). The siRNA sequences of the Cont siRNA were as follows: Sense, 5'-AuCaCgUaCgCgGaAuAcUuCgA-3' and antisense, 5'-uCgAaGuAuUcCgCgUaCgUgAu-3' (5). The lower-case letters represent 2'-O-methyl-modified nucleotides.

Cell culture. Human breast cancer MDA-MB-231/Luc cells stably expressing firefly luciferase were obtained from Cell BioLabs, Inc. (San Diego, CA, USA). Tamoxifen-resistant human breast cancer MCF-7-Luc (TamR-Luc\#1) cells stably expressing firefly pGL3-luciferase were donated by Dr. Kazuhiro Ikeda (Division of Gene Regulation and Signal Transduction, Research Center for Genomic Medicine, Saitama Medical University, Saitama, Japan). Human hepatocellular carcinoma HepG2 and human cervical carcinoma HeLa cells were obtained from the European Collection of Cell Cultures (Salisbury, UK). Human pancreatic carcinoma PANC-1 cells were provided by Dr. Fumitaka Takeshita (Division of Molecular and Cellular Medicine, National Cancer Center Research Institute, Tokyo, Japan). Murine Lewis lung carcinoma LLC and murine colon carcinoma Colon 26 cells were obtained from the Cell Resource Center for Biomedical Research, Tohoku University (Sendai, Japan).

LLC and Colon 26 cells were cultured in RPMI-1640 medium (Wako Pure Chemical Industries Inc.) with $10 \%$ heat-inactivated fetal bovine serum (FBS, Gibco; Thermo Fisher Scientific, Inc., Waltham, MA, USA) and $100 \mu \mathrm{g} / \mathrm{ml}$ kanamycin (Wako Pure Chemical Industries Inc.) in a humidified atmosphere containing $5 \% \mathrm{CO}_{2}$ at $37^{\circ} \mathrm{C}$. MCF-7-Luc cells were cultured in Dulbecco's modified Eagle's medium (DMEM; Wako Pure Chemical Industries Inc.) supplemented with $10 \% \mathrm{FBS}, 100 \mu \mathrm{g} / \mathrm{ml}$ kanamycin and $0.5 \mathrm{mg} / \mathrm{ml} \mathrm{G} 418$ at $37^{\circ} \mathrm{C}$ in a $5 \% \mathrm{CO}_{2}$ humidified atmosphere. MDA-MB-231/Luc and HepG2 cells were cultured in DMEM supplemented with $10 \% \mathrm{FBS}$ and $100 \mu \mathrm{g} / \mathrm{ml}$ kanamycin at $37^{\circ} \mathrm{C}$ in a $5 \% \mathrm{CO}_{2}$ humidified atmosphere. HeLa cells were cultured in Eagle's Minimum Essential Medium (Wako Pure Chemical Industries Inc.) supplemented with $10 \%$ FBS and $100 \mu \mathrm{g} / \mathrm{ml}$ kanamycin at $37^{\circ} \mathrm{C}$ in a $5 \% \mathrm{CO}_{2}$ humidified atmosphere.
PKN3 expression level in vitro. To investigate the PKN3 mRNA levels in tumor cells, total RNA was isolated from MDA-MB-231, MCF-7, PANC-1, HeLa, HepG2, LLC and Colon 26 cells using NucleoSpin RNA (Macherey-Nagel, Düren, Germany). For reverse transcription-polymerase chain reaction (RT-PCR), the $20-\mu 1$ reaction volume contained $1 \mu \mathrm{l}$ synthesized cDNA, 10 pmol of each specific primer pair (Fasmac Co., Ltd., Kanagawa, Japan) and 0.25 U Ex Taq DNA polymerase (Takara Bio, Inc., Otsu, Japan) with PCR buffer containing $1.5 \mathrm{mM} \mathrm{MgCl}_{2}$ and $0.25 \mathrm{mM}$ of each dNTP (Takara Bio, Inc., Otsu, Japan). The profile of PCR amplification consisted of denaturation at $95^{\circ} \mathrm{C}$ for $0.5 \mathrm{~min}$, primer annealing at $55^{\circ} \mathrm{C}$ for $0.5 \mathrm{~min}$, and elongation at $72^{\circ} \mathrm{C}$ for 1 min for 30 cycles. Human PKN3 cDNA (115 bp) was amplified using the following primers: Forward, 5'-CAC TTTGGGAAGGTCCTCCTG-3' and reverse, 5'-CGCAGT ACAGGCTCTCTATCT-3'. Mouse PKN3 cDNA (88 bp) was amplified using the following primers: Forward, 5'-TCA CCTTCTGCGAGCCTGTC-3' and reverse, 5'-ATGAAA TCCCGGCCTCTCCGC-3'. Human GAPDH cDNA (820 bp) was amplified using the following primers: Forward, 5'-ATG ACCCCTTCATTGACCTC-3' and reverse, 5'-AAGTGGTCG TTGAGGGCAAT-3'. Mouse $\beta$-actin cDNA (514 bp) was amplified using the following primers: Forward, 5'-TGTGAT GGTGGGAATGGGTCAG-3' and reverse, 5'-TTTGATGTC ACGCACGATTTCC-3'. The PCR products were analyzed by $18 \%$ acrylamide gel electrophoresis in a Tris-borate-EDTA buffer (Wako Pure Chemical Industries Inc.), and were visualized by ethidium bromide staining.

For knockdown of PKN3 mRNA by transfection of cells with PKN3 siRNA, MDA-MB-231, PANC-1, HeLa, LLC and Colon 26 cells were plated into 6 -well culture dishes at a density of $3 \times 10^{5}$ cells per well. The cells were transfected with $50 \mathrm{nM}$ Cont siRNA or PKN3 siRNA using Lipofectamine RNAiMax reagent (Invitrogen; Thermo Fisher Scientific, Inc.). Total RNA was isolated and quantitative RT-PCR was performed using a iCycler MyiQ detection system (Bio-Rad Laboratories, Hercules, CA, USA) and a SYBR Green I assay (iQ ${ }^{\mathrm{TM}}$ SYBER Green Supermix; Bio-Rad Laboratories) $48 \mathrm{~h}$ subsequent to transfection. Human and mouse PKN3 cDNAs were amplified using the aforementioned primers. Human $\beta$-actin cDNA (186 bp) was amplified using the following primers: Forward, 5'-TGGCACCCAGCACAATGAA-3' and reverse, 5'-CTAAGTCATAGTCCGCCTAGAAGCA-3'. Mouse $\beta$-actin cDNA (171 bp) was amplified using the following primers: Forward, 5'-CATCCGTAAAGACCTCTATGCCAAC-3' and reverse, 5'-ATGGAGCCACCGATCCACA-3'. Samples were run in triplicate and the expression levels of human PKN3 and mouse PKN3 mRNA were normalized to the quantity of human $\beta$-actin and mouse $\beta$-actin mRNA, respectively, in the same sample, and analyzed using the comparative $\mathrm{Cq}$ method (16).

Cell growth inhibition. MCF-7, MDA-MB-231, LLC and Colon 26 cells were seeded in 96-well plates at a density of $2 \times 10^{4}$ cells/well $24 \mathrm{~h}$ prior to transfection. Cells at $50 \%$ confluency were transfected with $50 \mathrm{nM}$ Cont siRNA or PKN3 siRNA using Lipofectamine RNAiMax reagent and then incubated for $48 \mathrm{~h}$. In the PKN3 siRNA or Cont siRNA with DXR combined treatment conditions, the cells were incubated 
for $2 \mathrm{~h}$ subsequent to transfection with $50 \mathrm{nM}$ PKN3 siRNA or Cont siRNA using Lipofectamine RNAiMax reagent, and then treated with various concentrations $(0.016-0.5 \mu \mathrm{M})$ of DXR for an additional $48 \mathrm{~h}$. The cell number was determined using Cell Counting Kit-8 (Dojindo Laboratories, Kumamoto, Japan). Cell viability was expressed relative to the absorbance of untreated cells at $450 \mathrm{~nm}$.

Preparation of liposome and lipoplexes. Cationic liposomes were prepared from DOTAP/Chol or DOTAP/DOPE at a molar ratio of 1:1 using a thin-film hydration method, as reported previously (17). To prepare the cationic liposome/siRNA complex (cationic lipoplex), cationic liposome suspension was mixed with siRNA by vortexing for $10 \mathrm{sec}$ at a charge ratio (+:-) of 4:1, and left for $15 \mathrm{~min}$ at room temperature. The theoretical charge ratio (+:-) of cationic liposome to siRNA was calculated as the molar ratio of DOTAP nitrogen to siRNA phosphate.

The particle size distributions of liposomes and lipoplexes were measured by the cumulant method using a light-scattering photometer (ELS-Z2, Otsuka Electronics Co., Ltd., Osaka, Japan) at $25^{\circ} \mathrm{C}$ subsequent to diluting the dispersion to an appropriate volume $(\sim 1.5 \mathrm{ml})$ with water. The zeta-potentials were measured by electrophoresis light-scattering methods using ELS-Z2 at $25^{\circ} \mathrm{C}$ subsequent to diluting the dispersion to an appropriate volume $(\sim 1.5 \mathrm{ml})$ with water. Cationic liposomes were $\sim 100 \mathrm{~nm}$ in size and had a zeta-potential of $\sim 53 \mathrm{mV}$. The lipoplex size was $\sim 340 \mathrm{~nm}$ and the zeta-potential was $\sim 41 \mathrm{mV}$.

Liver and lung metastasis model. All animal experiments were performed with approval from the Institutional Animal Care and Use Committee of Hoshi University (Tokyo, Japan). To generate the mouse model of liver metastasis, $1.0 \times 10^{6}$ MCF-7 or MDA-MB-231 cells suspended in $50 \mu \mathrm{l}$ PBS (pH 7.4) containing 50\% reconstituted basement membrane (Matrigel; BD Biosciences, Franklin Lakes, NJ, USA) were inoculated into the spleen of female BALB/c nu/nu mice (18-20 g; 8 weeks of age; CLEA Japan, Inc., Tokyo, Japan). To generate mice with lung metastases, $1.0 \times 10^{6} \mathrm{MCF}-7$ and LLC cells were injected intravenously into the tail vein of female BALB/c nu/nu mice and female C57BL/6 N mice (18-20 g; 8 weeks of age; Sankyo Laboratory Service Corporation, Tokyo, Japan), respectively.

In vivo therapy for liver MDA-MB-231 metastasis. For efficient delivery of siRNA into liver metastasis, DOTAP/Chol lipoplex with $50 \mu \mathrm{g}$ siRNA was administered intravenously into mice bearing liver metastases $1 \mathrm{~min}$ subsequent to the intravenous injection of $1 \mathrm{mg}$ chondroitin sulfate (sequential injection method) (14). On day 32 subsequent to inoculation of MDA-MB-231/Luc cells into the spleen of mice, DXR was administered intravenously at $3 \mathrm{mg} / \mathrm{kg}$ via the lateral tail vein, and then Cont siRNA or PKN3 siRNA was administered to mice using a sequential injection method at $1 \mathrm{~h}$ subsequent to injection of DXR. On days 34, 36 and 38 subsequent to inoculation, Cont siRNA or PKN3 siRNA was administered to mice using a sequential injection method. On day 40 subsequent to inoculation, mice were sacrificed by cervical dislocation, and the excised livers were then weighed.
To examine the expression level of PKN3 and vascular endothelial growth factor (VEGF) mRNA in MDA-MB-231 tumors that metastasized to the liver, total RNA was isolated from the excised livers using TRI Reagent (Molecular Research Center, Inc., Cincinnati, OH, USA). RNA yield and purity were checked by spectrometric measurements at 260 and $280 \mathrm{~nm}$. cDNA was synthesized from total RNA using a PrimeScript RT Reagent kit with gDNA Eraser (Takara Bio Inc., Otsu, Japan). Quantitative PCR was performed using Takara Thermal Cycler Dice (Takara Bio Inc.) and TaqMan Gene expression assays (Pkn3, Mm00464275_m1; Vegfa, Mm00437306_m1; Gapdh, Mm99999915_g1; Applied Biosystems ${ }^{\circledR}$; Thermo Fisher Scientific, Inc.). Samples were run in triplicate, and the expression levels of PKN3 and VEGF mRNA were normalized to the amount of GAPDH mRNA in the same sample, and analyzed using the comparative $\mathrm{Cq}$ method (16).

Furthermore, to examine the antiangiogenic effect of PKN3 siRNA on MDA-MB-231 tumors that metastasized to the liver, excised livers were frozen on dry ice and sliced to $16 \mu \mathrm{m}$ thickness. The sections were incubated with rat anti-mouse CD31 (PECAM-1) monoclonal antibody (cat. no. 550274; dilution 1:50; clone, MEC 13.3; BD Pharmingen, San Diego, CA, USA), for the detection of mouse endothelial cells, and subsequently incubated with goat anti-rat IgG conjugated to Alexa Fluor 488 (cat. no. A11006; dilution, 1:1,000; Invitrogen; Thermo Fisher Scientific, Inc.), as a secondary antibody. Immunofluorescence was examined microscopically using an ECLIPSE TS100-F microscope at a magnification of x100 (Nikon, Tokyo, Japan).

In vivo therapy for liver MCF-7 metastases. On day 8 subsequent to inoculation of MCF-7-Luc cells into the spleen of mice, $3 \mathrm{mg} / \mathrm{kg}$ DXR was administered intravenously via the lateral tail vein and then $50 \mu \mathrm{g}$ Cont siRNA or PKN3 siRNA was administered to mice using sequential injections at $1 \mathrm{~h}$ subsequent to the injection of DXR. On days 10, 12, and 14 following inoculation, $50 \mu \mathrm{g}$ Cont siRNA or PKN3 siRNA was administered into the mice using sequential injections. At day 16 subsequent to inoculation, mice were sacrificed by cervical dislocation, and the excised livers were weighed. The luciferase activities in the livers were measured as previously described (14). Luciferase activity (\%) was calculated relative to the luciferase activity (cps/organ) of untreated liver.

Distribution of DXR in MCF-7 tumors that metastasized to the liver. On day 15 subsequent to the inoculation of MCF-7-Luc cells into the spleen of mice, $3 \mathrm{mg} / \mathrm{kg}$ DXR was administered intravenously via the lateral tail vein. At $1 \mathrm{~h}$ after injection of DXR, $50 \mu \mathrm{g}$ Cont siRNA or PKN3 siRNA was administered to the mice using sequential injections with chondroitin sulfate and DOTAP/Chol lipoplexes. Twenty-four h after injection of cationic lipoplex, the mice were sacrificed by cervical dislocation. The tumors that metastasized to the liver were excised, and then homogenized in $0.1 \mathrm{M} \mathrm{NH}_{4} \mathrm{Cl} / \mathrm{NH}_{3}$ buffer ( $\mathrm{pH} 9.0$ ). DXR was extracted with chloroform/methanol (2:1 v/v) and analyzed by high-performance liquid chromatography, as previously described (18).

In vivo therapy for lung MCF-7 and LLC metastatic tumors. For efficient delivery of siRNA to lung metastases, DOTAP/DOPE 
A

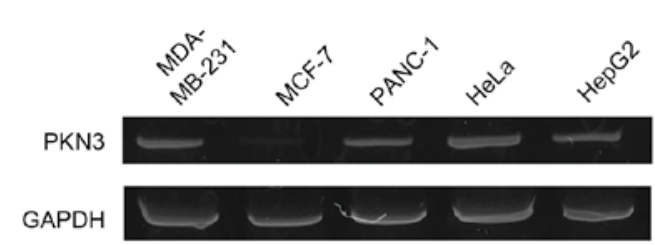

Mouse cell lines

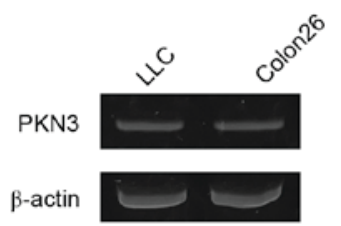

B

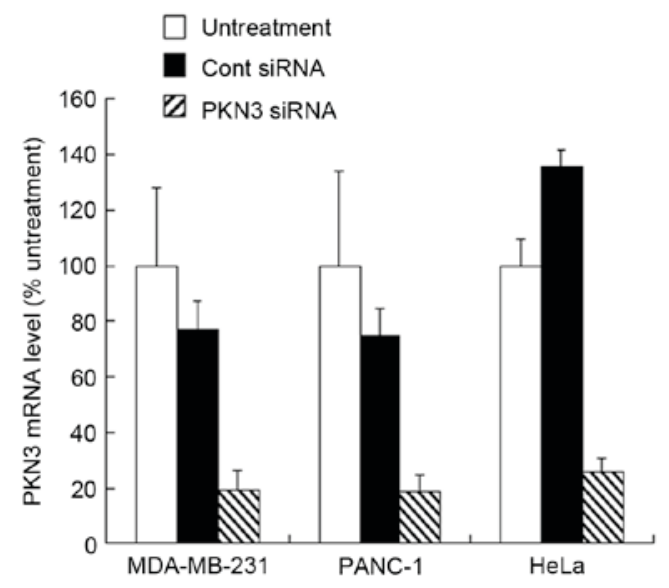

C

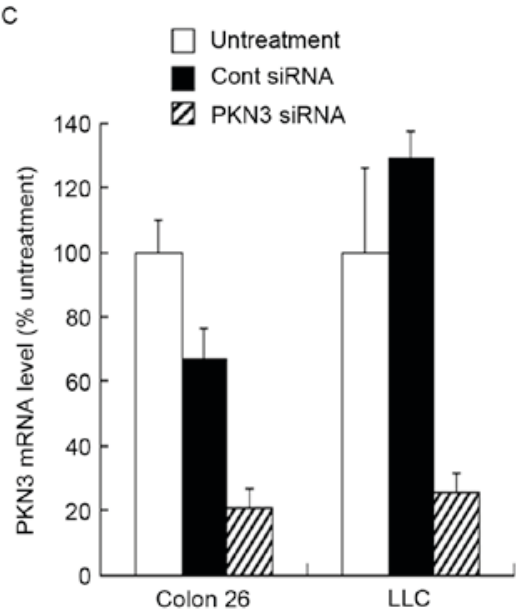

Figure 1. Expression of PKN3 mRNA and suppression of PKN3 mRNA by transfection with PKN3 small interfering RNA (siRNA) in human and mouse tumor cell lines. (A) The expression levels of PKN3 mRNA in human and mouse tumor cell lines were analyzed by reverse transcription-polymerase chain reaction (RT-PCR). (B) Human MDA-MB-231, PANC-1 and HeLa cells, and (C) mouse LLC and Colon 26 cells were transfected with $50 \mathrm{nM}$ Cont siRNA or PKN3 siRNA using Lipofectamine RNAiMax reagent, and the expression levels of PKN3 mRNA in the cells were analyzed by RT-quantitative PCR (RT-qPCR). Each result represents the mean \pm standard deviation $(n=3)$. PKN3, protein kinase N3; siRNA, small interfering RNA; Cont, control.

lipoplexes were used (11). On day 5 after inoculation of MCF-7-Luc or LLC cells by intravenous injection into mice, DXR was administered intravenously at $3 \mathrm{mg} / \mathrm{kg}$ via the lateral tail vein, and then DOTAP/DOPE lipoplexes with $50 \mu \mathrm{g}$ of Cont siRNA or PKN3 siRNA were administered intravenously to mice at $1 \mathrm{~h}$ after DXR administration. On days 7, 9, and 11 after inoculation, Cont siRNA or PKN3 siRNA was administered intravenously by injection of DOTAP/DOPE lipoplexes. At day 13 after inoculation, the mice were sacrificed by cervical dislocation, and then the excised lungs were weighed.

Statistical analysis. The statistical significance of differences between mean values was determined by Student's t-test using GraphPad Prism (version 4.0; GraphPad Software Inc., La Jolla, CA, USA). P $\leq 0.05$ was considered to indicate a statistically significant difference.

\section{Results}

Expression level of PKN3 mRNA. To investigate PKN3 mRNA expression in culture cells, the human tumor MDA-MB-231, MCF-7, PANC-1, HeLa and HepG2 cell lines, and mouse tumor Colon 26 and LLC cell lines were used. Human PKN3 mRNA was expressed in MDA-MB-231, PANC-1, HeLa and HepG2 cells, but not in MCF-7 cells (Fig. 1A). By contrast, mouse PKN3 mRNA was expressed in LLC and Colon 26 cells (Fig. 1A). Previously, it has been reported that PKN3 is expressed in breast tumor cell lines, including MDA-MB-231 and MCF-7 cells (19); however, certain studies have reported that PKN3 is expressed in MDA-MB-231 cells, but not in MCF-7 cells $(20,21)$, which was consistent with the present results. Therefore, in subsequent experiments, the MDA-MB-231, PANC-1, HeLa, Colon 26 and LLC cells were used as PKN3-positive cell lines and MCF-7 cells as the PKN3-negative cell line.

Subsequently, whether transfecting PKN3 siRNA into the cells decreased the expression level of PKN3 mRNA was investigated. Lipofectamine RNAiMax was used as an in vitro transfection reagent for siRNA. When transfected into MDA-MB-231, PANC-1, HeLa, Colon 26 and LLC cells, PKN3 siRNA significantly inhibited the expression of human and mouse PKN3 mRNA compared with Cont siRNA $(\mathrm{P}<0.01)$ (Fig. 1B and C). By contrast, Cont siRNA did not markedly affect the expression of PKN3 mRNA in the cells.

Antiproliferative activity. To examine whether transfection with PKN3 siRNA could induce suppression of cell growth, cell viability was measured $48 \mathrm{~h}$ subsequent to transfection of MDA-MB-231, MCF-7, Colon 26 and LLC cells with PKN3 siRNA. However, transfection with PKN3 siRNA did not inhibit tumor growth in all the cell lines (Fig. 2A and B), indicating that suppression of PKN3 expression did not affect tumor growth in vitro.

Subsequently, whether transfection with PKN3 siRNA could increase the growth inhibitory effect of DXR treatment in tumor cells was evaluated. MCF-7, MDA-MB-231, Colon 26 and LLC cells were transfected with PKN3 siRNA, and $2 \mathrm{~h}$ later the cells were treated with various concentrations of DXR for $48 \mathrm{~h}$. However, the transfection of PKN3 siRNA did not affect the cytotoxicity of DXR in any cell lines (Fig. 3A-D). These data indicated that a reduction of PKN3 expression did not increase the sensitivity to DXR in tumor cells. 
A

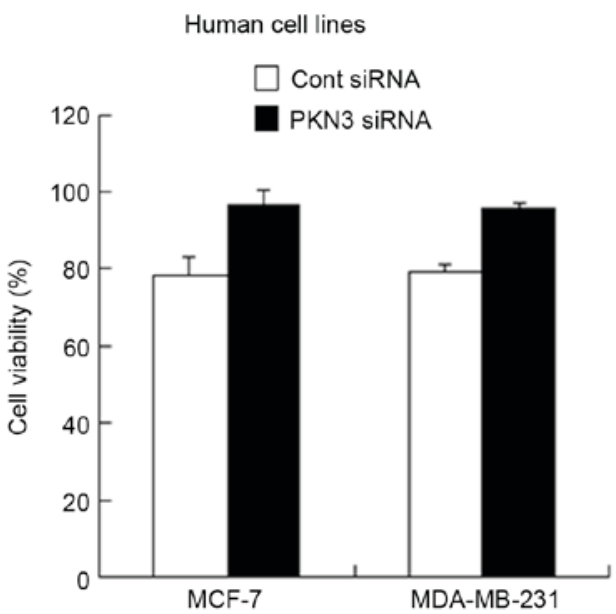

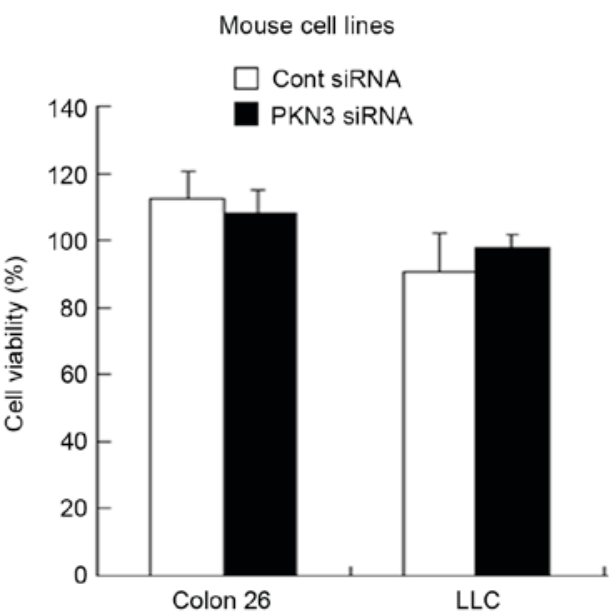

Figure 2. Anti-proliferative effects of PKN3 siRNA $48 \mathrm{~h}$ subsequent to transfection of cells with PKN3 siRNA. Following transfection with $50 \mathrm{nM}$ PKN3 siRNA, cell viability in (A) MCF-7 and MDA-MB-231 cells, and (B) Colon 26 and LLC cells was measured. Each column shows the mean \pm standard deviation $(\mathrm{n}=4)$. PKN3, protein kinase N3; siRNA, small interfering RNA; Cont, control.

A

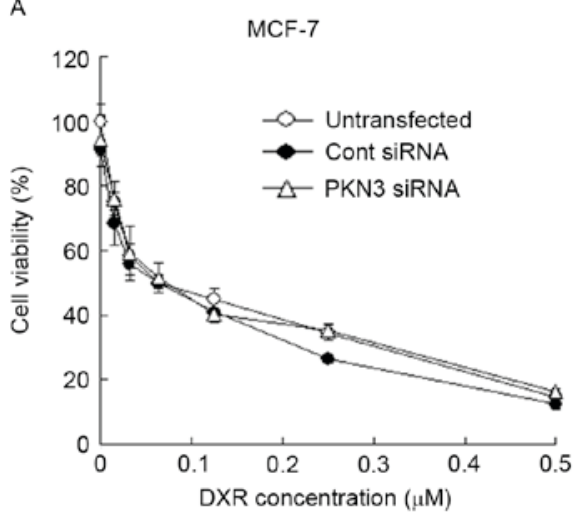

C

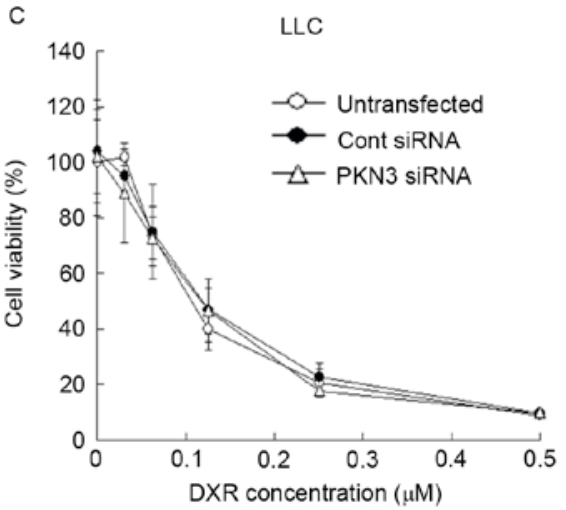

B

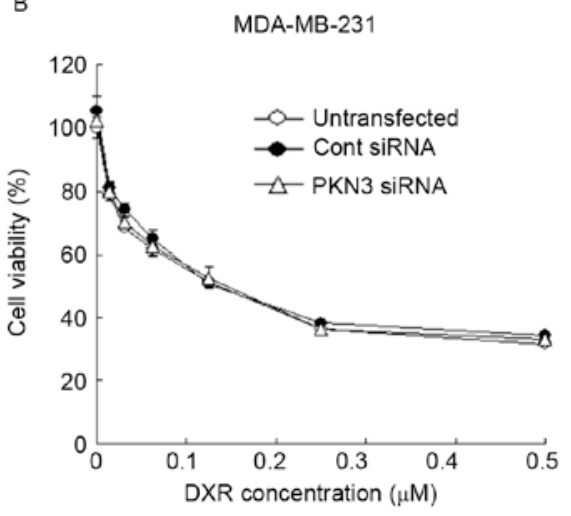

D

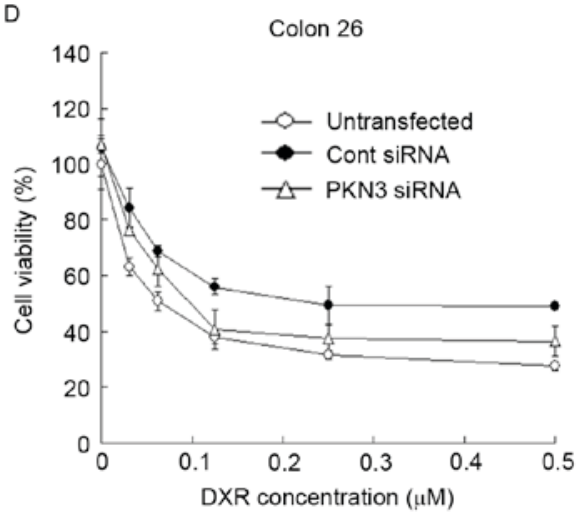

Figure 3. Dose effect of DXR on cytotoxicity in (A) MCF-7, (B) MDA-MB-231, (C) LLC and (D) Colon 26 cells at 2 h after transfection of cells with PKN3 siRNA. The cells were transfected with Cont siRNA or PKN3 siRNA for $2 \mathrm{~h}$, and then were treated with various concentrations of DXR for another $48 \mathrm{~h}$. The number of viable cells was determined using a WST-8 assay. Each result represents the mean \pm standard deviation ( $\mathrm{n}=4$ ). PKN3, protein kinase N3; Cont, control; siRNA, small interfering RNA; DXR, doxorubicin.

Therapeutic efficacy against liver MDA-MB-231-metastasized tumors. Subsequently, the in vivo efficacy of PKN3 siRNA and DXR combination therapy in inhibiting the growth of MDA-MB-231 tumors that metastasized to the liver was investigated. Injection of PKN3 siRNA was performed a total of four times, with 2 days between each injection. DXR was administered at a dose of $3 \mathrm{mg} / \mathrm{kg}$ at $1 \mathrm{~h}$ prior to the first injection of siRNA lipoplex. The anti-metastatic effect was evaluated by measurement of liver weight (mg) (Fig. 4A) or liver weight relative to body weight (\%) (Fig. 4B). A normal mouse liver ( 8 weeks of age) is $\sim 1,300 \mathrm{mg}$ in weight and accounts for $6.5 \%$ of body weight (data not shown). The four injections of PKN3 siRNA significantly suppressed the increase in weight of livers with MDA-MB-231 metastasis $(1,320 \pm 62 \mathrm{mg})$ compared with no treatment $(1,712 \pm 188 \mathrm{mg}$; $\mathrm{P}<0.01)$ or Cont siRNA $(1,643 \pm 173 \mathrm{mg} ; \mathrm{P}<0.05)$, but PKN3 
A

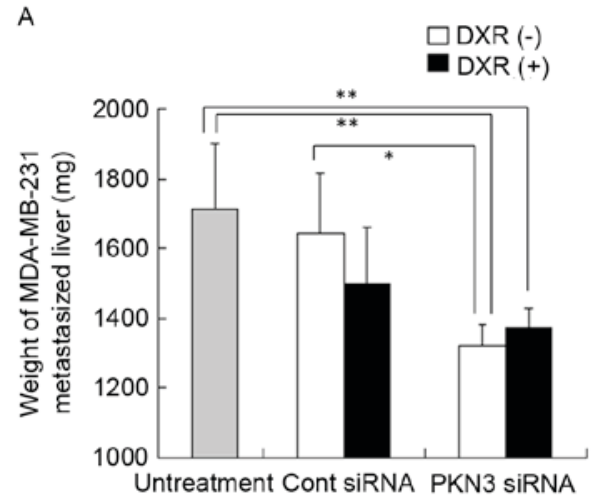

B

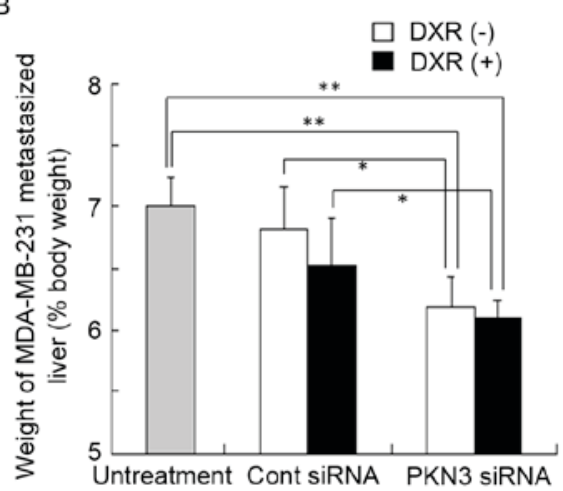

$c$

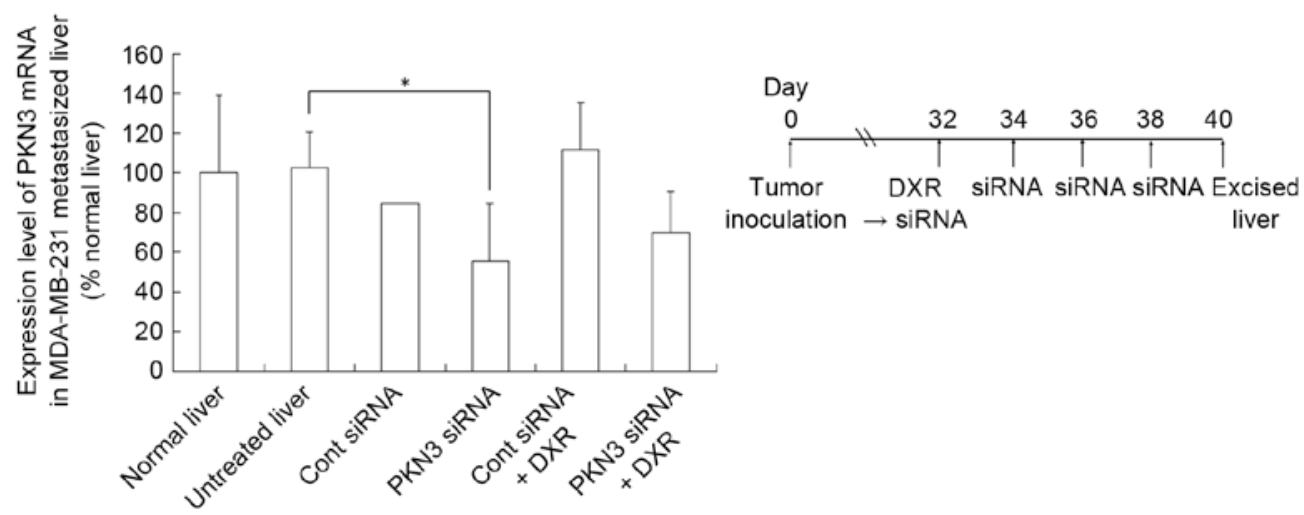

Figure 4. In vivo combination therapy of PKN3 siRNA and DXR for mice with liver MDA-MB-231 metastasis. In (A and B), DXR, followed by PKN3 siRNA was administered to mice on day 32 after inoculation, and PKN3 siRNA was administered on days 34, 36, and 38. The mice were sacrificed at day 40, and then the excised livers were weighed. Each result represents the mean \pm standard deviation $(\mathrm{n}=4-5)$. ${ }^{*} \mathrm{P}<0.05$; ${ }^{* *} \mathrm{P}<0.01$. In $(\mathrm{C})$, mouse PKN3 mRNA level in tumor-metastasized liver shown in $(\mathrm{A}$ and $\mathrm{B})$. Each result represents the mean $(\mathrm{n}=2$ for Cont siRNA) or the mean \pm standard deviation $(\mathrm{n}=4)$. $\mathrm{P}<0.05$. $\mathrm{PKN} 3$, protein kinase N3; Cont, control; siRNA, small interfering RNA; DXR, doxorubicin.

siRNA plus DXR did not reduce liver weight $(1,370 \pm 59 \mathrm{mg})$ compared with PKN3 siRNA alone (Fig. 4A and B).

To examine whether this antitumor effect was dependent on the suppression of PKN3 expression, human and mouse PKN3 mRNA levels in livers with MDA-MB-231 metastasis were measured by quantitative RT-PCR analysis; however, human PKN3 and GAPDH mRNA levels in certain tumors were below the detection limit by quantitative PCR analysis (data not shown). For mouse PKN3 mRNA levels, repeated injections of PKN3 siRNA significantly decreased PKN3 mRNA levels compared with those in untreated livers $(\mathrm{P}<0.05$; Fig. 4C), indicating that PKN3 siRNA could suppress expression of PKN3 mRNA in vivo.

Vascular structure of tumors after injection of PKN3 siRNA. To investigate the mechanism of the antitumor effect of PKN3 siRNA on liver MDA-MB-231 metastases, the vascular structure following repeated injections of PKN3 siRNA was examined. Treatment of metastasis with PKN3 siRNA and PKN3 siRNA combined with DXR induced apparent changes in vascular structure (Fig. 5A). Treatment with PKN3 siRNA reduced narrow vessels in tumors and increased open vessels. This histological change in tumor vasculature subsequent to treatment with PKN3 siRNA appeared to be similar to 'normalization' of tumor vasculature (22).

Vascular endothelial growth factor (VEGF) protein is a prominent cytokine that promotes endothelial cell proliferation during angiogenesis (23). Therefore, the present study investigated whether treatment with PKN3 siRNA affected the expression level of VEGF mRNA in livers with MDA-MB-231 metastases by quantitative RT-PCR analysis. Treatment with PKN3 siRNA significantly decreased mouse VEGF mRNA levels in the liver compared with that in untreated livers $(\mathrm{P}<0.05$; Fig. 5B), indicating that the change in vascular structure may be caused by a decrease in VEGF expression.

Therapeutic efficacy against liver MCF-7-metastasized tumors. To examine whether PKN3 siRNA could exhibit antitumor effects, regardless of the expression of PKN3 mRNA in tumor cells, the efficacy of PKN3 siRNA combined with DXR against liver MCF-7-Luc metastasis was investigated. Since this liver metastasis model rapidly led to moribund recipient mice, combination therapy was commenced at 8 days subsequent to tumor cell challenge. Repeated injections of PKN3 siRNA or a single injection of DXR could not suppress the increase in weight of livers with MCF-7-Luc metastasis $(2,230 \pm 303$ and $1,983 \pm 356 \mathrm{mg}$, respectively), compared with no treatment $(2,160 \pm 174 \mathrm{mg})$ or Cont siRNA $(2,163 \pm 289 \mathrm{mg})$; however, combination treatment significantly inhibited the increase in liver weight $(1,593 \pm 131 \mathrm{mg}$; $\mathrm{P}<0.01)$ (Fig. 6A and B).

Luciferase activity in livers with MCF-7-Luc metastasis indicated the number of living tumor cells. Therefore, the present study measured luciferase activity in the livers subsequent to combination therapy. Treatment with PKN3 siRNA 

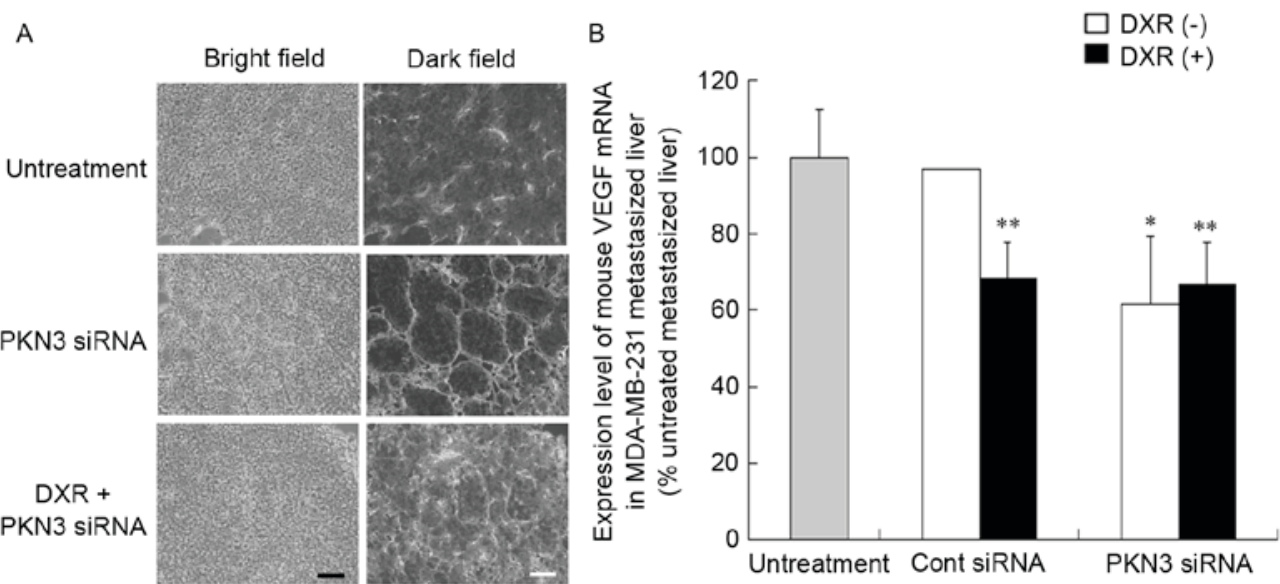

Figure 5. Change in vascular vessels in liver metastasized MDA-MB-231 tumors after combination therapy of PKN3 siRNA and DXR. (A) Immunostaining for endothelial cells in tumors shown in Fig. 4. White signals indicate CD31-positive endothelial cells. Scale bar, $100 \mu \mathrm{m}$. (B) Mouse VEGF mRNA level in livers with MDA-MB-231 tumor metastasis. Each result represents the mean ( $\mathrm{n}=2$ for Cont siRNA) or the mean \pm standard deviation $(\mathrm{n}=4)$. " $\mathrm{P}<0.05$, ${ }^{* *} \mathrm{P}<0.01$, compared with no treatment. PKN3, protein kinase N3; Cont, control; siRNA, small interfering RNA; DXR, doxorubicin.

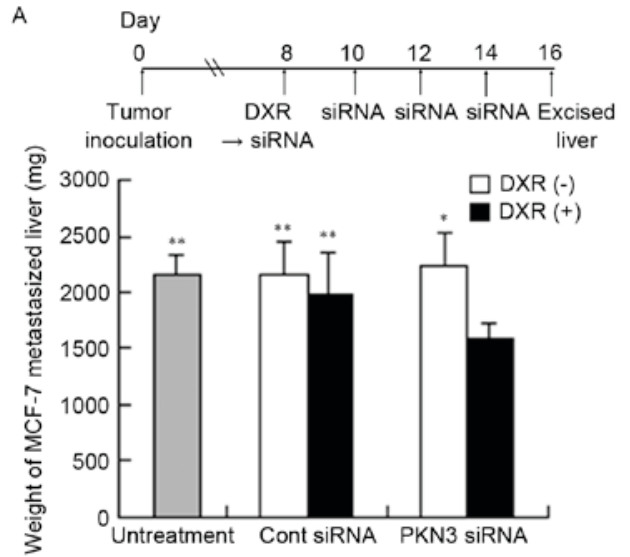

B
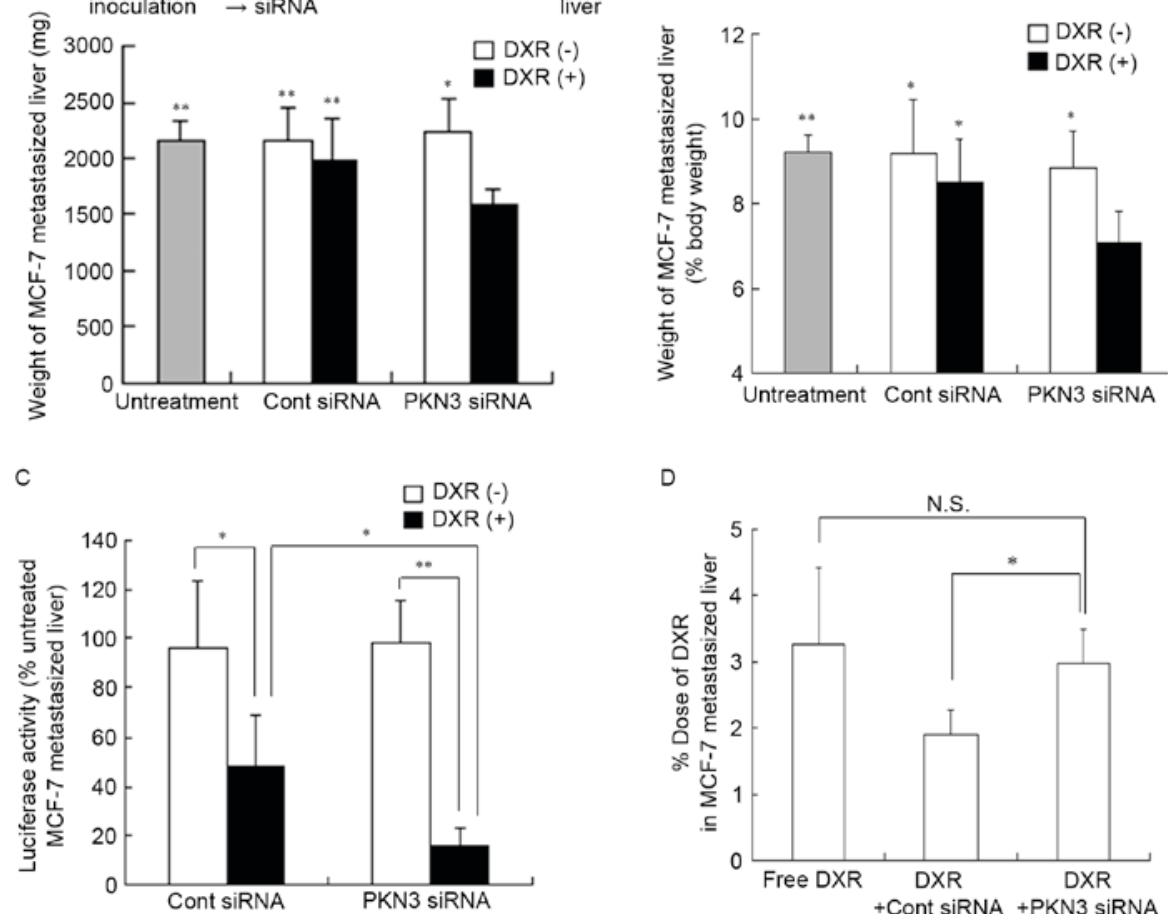

Figure 6. In vivo combination therapy with PKN3 siRNA and DXR in mice with liver MCF-7 metastasis. In (A-C), DXR, followed by PKN3 siRNA was administered to mice on day 8 after inoculation, and PKN3 siRNA was administered on days 10,12, and 14. The mice were sacrificed at day 16 after inoculation, and then the excised livers were weighed. In (C), the luciferase activities in livers shown in (A and B) were measured. Luciferase activity (\%) was calculated relative to the luciferase activity (cps/organ) of untreated liver. In (A-C), each result represents the mean \pm standard deviation ( $\mathrm{n}=4-6)$. In (A and B), ${ }^{*} \mathrm{P}<0.05,{ }^{* *} \mathrm{P}<0.01$, compared with PKN3 siRNA and DXR. In (D), on day 15 after the inoculation, DXR, followed by PKN3 siRNA was administered to mice. DXR concentrations in livers were measured at $24 \mathrm{~h}$ after injection of siRNA by high-performance liquid chromatography (HPLC). Each column shows the mean \pm standard deviation $(\mathrm{n}=3)$. In $(\mathrm{C}$ and $\mathrm{D}),{ }^{*} \mathrm{P}<0.05,{ }^{* *} \mathrm{P}<0.01$. N.S., not significant; PKN3, protein kinase N3; Cont, control; siRNA, small interfering RNA; DXR, doxorubicin.

did not decrease luciferase activity in the metastatic tumors, but a combination of Cont siRNA plus DXR significantly reduced luciferase activity compared with Cont siRNA $(\mathrm{P}<0.05)$ (Fig. 6C). However, the liver weight was not significantly different between the groups (Fig. 6A), indicating that a single injection of DXR may be effective for the treatment of liver MCF-7 metastasis. Furthermore, the luciferase activity following combination therapy with PKN3 siRNA and DXR was significantly decreased compared with the activity subsequent to injections of PKN3 siRNA $(\mathrm{P}<0.01)$ and subsequent 
A
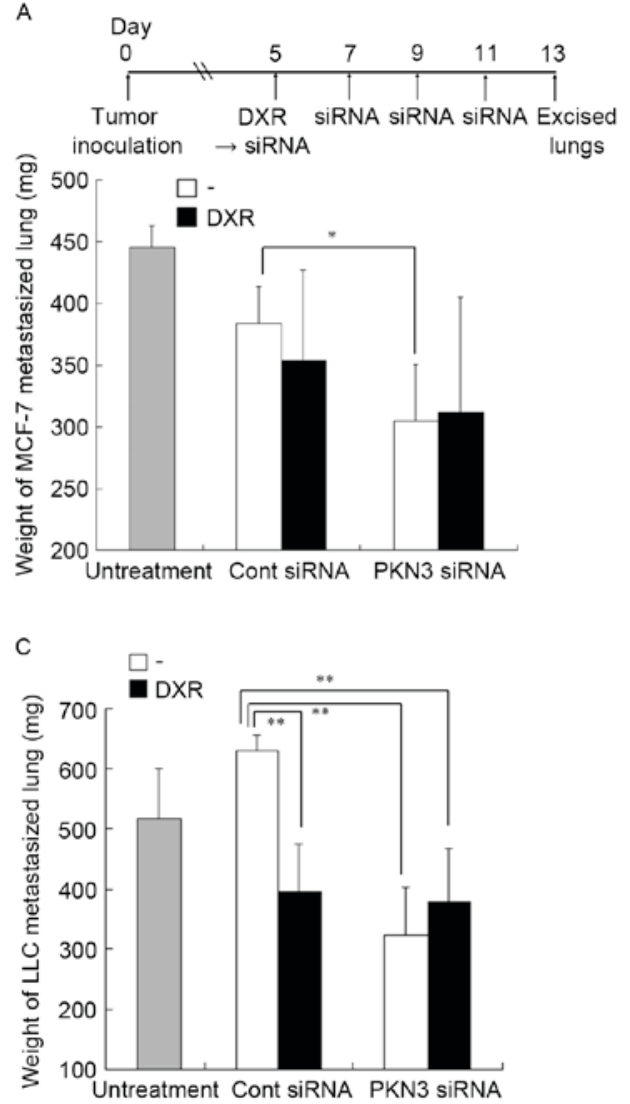

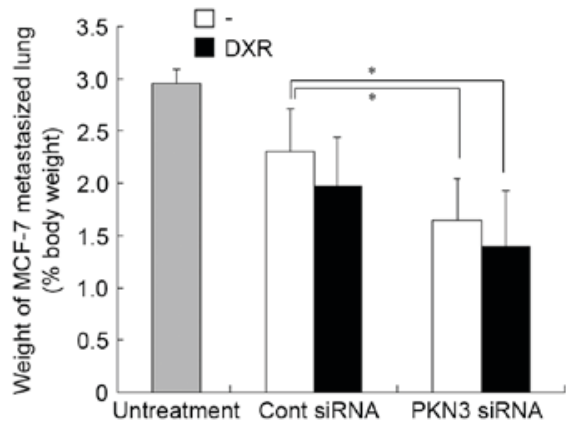

D

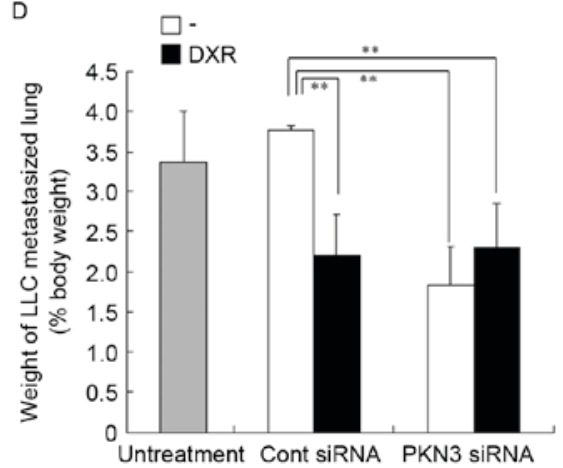

Figure 7. In vivo combination therapy of PKN3 siRNA and DXR for lung MCF-7- (A and B) and LLC-metastasized mice (C and D). (A-D) DXR, followed by PKN3 siRNA was administered to mice on day 5 subsequent to inoculation, and PKN3 siRNA was administered on days 7,9 and 11. The mice were sacrificed at day 13 after inoculation, and then the excised livers were weighed. In (A and B), each result represents the mean $+\operatorname{standard~deviation~(~} n=4-5)$. In $(C$ and $D)$, each result represents the mean \pm standard deviation $(n=3-5)$. $P<0.05,{ }^{* *} \mathrm{P}<0.01$. PKN3, protein kinase N3; siRNA, small interfering RNA; DXR, doxorubicin.

to combination therapy with Cont siRNA and DXR $(\mathrm{P}<0.05)$ (Fig. 6C), indicating that PKN3 siRNA could increase the therapeutic efficacy of DXR for liver MCF-7-Luc metastasis. These findings suggested that PKN3 siRNA may increase antitumor effects by suppression of PKN3 in mouse stroma cells, such as endothelial cells, but not tumor cells, as MCF-7 cells do not express PKN3 (Fig. 1A).

Additionally, to investigate the mechanism of how PKN3 siRNA enhanced antitumor activity by DXR in vivo, the concentration of DXR in liver MCF-7 metastasis was measured at $24 \mathrm{~h}$ subsequent to a single injection of PKN3 siRNA that was administered following DXR administration. However, PKN3 siRNA did not significantly increase the accumulation of DXR in the liver compared with the administration of free DXR solution (Fig. 6D), indicating that treatment with PKN3 siRNA did not affect the accumulation of DXR in liver MCF-7 metastasis.

Therapeutic efficacy against lung MCF-7 and LLC metastasis. To investigate whether treatment with PKN3 siRNA could inhibit lung metastasis, combination therapy with PKN3 siRNA and DXR for lung MCF-7 and LLC metastases was examined. Since the two lung metastasis models rapidly led to moribund recipient mice, combination therapy was started on day 5 after tumor cell challenge. Normal mouse lungs are $\sim 150 \mathrm{mg}$ in weight and represent $0.75 \%$ of body weight (data not shown). In lung MCF-7 metastasis, repeated injections of
PKN3 siRNA significantly suppressed the increase in weight of lungs with metastasis $(305 \pm 45 \mathrm{mg})$, compared with no treatment $(446 \pm 16 \mathrm{mg} ; \mathrm{P}<0.01)$ or Cont siRNA $(384 \pm 30 \mathrm{mg}$; $\mathrm{P}<0.05$ ) (Fig. 7A and B). However, the combination of PKN3 siRNA and DXR did not induce a decrease in lung weight $(312 \pm 93 \mathrm{mg})$ compared with PKN3 siRNA alone. In lung LLC metastasis, repeated injections of PKN3 siRNA or a single injection of DXR significantly suppressed the increase in the weight of lungs with LLC metastasis $(323 \pm 79 \mathrm{mg}$ and $396 \pm 77 \mathrm{mg}$, respectively), compared with Cont siRNA (630 $\pm 26 \mathrm{mg}$; P $<0.01$ ) (Fig. 7C and D). However, the combination with PKN3 siRNA and DXR could not reduce lung weight (378 $\pm 88 \mathrm{mg}$ ) compared with PKN3 siRNA. These findings suggested that PKN3 siRNA could suppress tumor growth in lung metastases, but could not increase the antitumor effect of DXR.

\section{Discussion}

The present study investigated whether PKN3 siRNA and DXR combination therapy could increase the inhibition of tumor growth induced by DXR or PKN3 siRNA alone in vitro and in vivo. It has been reported that the expression of PKN3 mRNA was relatively restricted to specific tissues, including the skeletal muscle, heart and liver in normal tissues (20), primary vascular endothelial HUVEC cells and endothelial lymphatic HMVEC-LLy cells (5). Aleku et al (5) reported 
that transfection of PKN3 siRNA into cultured primary endothelial cells revealed an essential role of PKN3 in endothelial tube formation and migration. Furthermore, liposomal PKN3 siRNA (Atu027) showed an inhibitory effect on invasive tumor growth and regional lymph node metastasis in mice bearing orthotropic pancreatic and prostate cancer (6). In the present study, treatment of liver or lung metastases with PKN3 siRNA could suppress tumor growth in vivo (Figs. 4 and 7), although it did not exhibit inhibition of cell growth in vitro (Fig. 2). Furthermore, PKN3 siRNA reduced tumor growth of lung PKN3-negative metastasis, as well as PKN3-positive metastasis (Fig. 7). These findings suggested that the antitumor effect of PKN3 siRNA on the metastases may be due to inhibition of endothelial function via knockdown of PKN3 expression in endothelial cells.

Adhesive interactions between tumor cells and endothelial cells are initial key events in the extravasation of tumor cells from the blood stream into underlying tissues. Firm adhesion of tumor cells to endothelial cells is mediated by cell adhesion molecules, such as intercellular adhesion molecule-1 (ICAM-1) and vascular cell adhesion molecule-1 (VCAM-1), leading to tumor invasion $(24,25)$. ICAM-1 is a central adhesion molecule that is important for binding and signaling between vascular endothelial cells and tumor cells during tumor metastasis (26). Recently, it has been reported that PKN3-knockdown mice are viable and develop normally, but the mice exhibited impaired lung metastasis of tumor cells subsequent to intravenous injection (27). It was also found that PKN3 knockdown induced a glycosylation defect in cell-surface glycoproteins, including ICAM-1, integrin $\beta 1$, and integrin $\alpha 5$ in HUVEC cells. Furthermore, Atu027-treated HUVEC cells showed elevated expression of VE-cadherin, a major protein involved in adherence junction integrity, indicating that knockdown of PKN3 siRNA induced an elevation of VE-cadherin in vascular endothelial cells and prevented tumor metastasis through enhancement of the endothelial barrier (6). These findings suggested that knockdown of PKN3 in stroma cells, such as endothelial cells, may inhibit tumor metastasis via an increase in the endothelial barrier or a decrease in binding between vascular endothelial cells and tumor cells. Following the present study, to elucidate the mechanism of the antitumor effect of PKN3 siRNA, additional studies should be performed to investigate the expression level of VE-cadherin and changes in glycosylation in ICAM-1 in the metastasis subsequent to treatment with PKN3 siRNA.

Repeated injections of PKN3 siRNA were effective against liver MDA-MB-231 metastasis and lung MCF-7 and LLC metastases, but not liver MCF-7 metastasis (Figs. 4, 6 and 7). The therapeutic efficacy against lung LLC metastasis in the present study $(2.5 \mathrm{mg}$ PKN3 siRNA/kg mouse, a total of four times) was extremely similar to a previous finding (6) that LLC metastasis in the lungs was significantly inhibited in mice repeatedly treated with Atu027 at $2.8 \mathrm{mg}$ PKN3 siRNA/kg mouse (a total of nine times), indicating that DOTAP/DOPE liposomes could deliver PKN3 siRNA into lung metastasis, as well as Atu027. It was previously reported that repeated injections of PKN3 siRNA (a total of five times) could inhibit liver MCF-7 metastasis (14). However, in the present study, no inhibitory effect was observed after repeated injections of PKN3 siRNA (a total of four times) in liver MCF-7 metastasis (Fig. 6A and B). It was hypothesized that a difference in administration schedule between the previous study and the present study may have affected the therapeutic efficacy. However, it was not clear why repeated injections of PKN3 siRNA suppressed lung MCF-7 metastasis, but not liver MCF-7 metastasis using the same administration schedule. In the present study, PKN3 siRNA was transfected into liver metastasis using sequential injections of chondroitin sulfate and DOTAP/Chol lipoplex, and into lung metastasis by injections of DOTAP/DOPE lipoplex. The difference in transduction efficiencies between the injection methods into MCF-7 metastases may affect the therapeutic efficacy of PKN3 siRNA.

It has been reported that knockdown of PKN3 in vascular endothelial cells induced an enhancement of the endothelial barrier via an elevation of VE-cadherin (6), indicating that injection of PKN3 siRNA may be able to decrease the efflux of DXR accumulated in tumor metastasis into the blood flow; therefore, for in vivo combination therapy, DXR was injected prior to injections of PKN3 siRNA. However, in vivo treatment with PKN3 siRNA could not increase therapeutic efficacy by DXR for liver MDA-MB-231 metastasis (Fig. 4A and B) and lung MCF-7 and LLC metastases (Fig. 7), with the exception of liver MCF-7 metastasis (Fig. 6A and B), indicating that combination therapy with PKN3 siRNA and DXR could not induce synergistic or additive antitumor effects for their metastases. Additional studies should be performed to elucidate why treatment with PKN3 siRNA using sequential injections of chondroitin sulfate and DOTAP/Chol lipoplexes increased the therapeutic efficacy of DXR only for liver MCF-7 metastasis.

In conclusion, the present study demonstrated that PKN3 siRNA reduced tumor growth of liver and lung metastases, regardless of PKN3 expression in tumor cells, but the combination with DXR did not increase therapeutic efficacy. Although PKN3 siRNA may induce antitumor effects in metastases by suppression of PKN3 mRNA in stroma cells, such as endothelial cells, rather than tumor cells, PKN3 may be a promising therapeutic target for the treatment of lung and liver metastases.

\section{Acknowledgements}

The authors thank Ms. Chiho Amiya and Ms. Natsumi Yamamoto (Department of Drug Delivery Research, Hoshi University, Tokyo, Japan) for assistance with experimental work. This study was supported in part by a Grant-in-Aid for Scientific Research (C) from the Japan Society for the Promotion of Science (grant no. 26460046).

\section{References}

1. Aagaard L and Rossi JJ: RNAi therapeutics: Principles, prospects and challenges. Adv Drug Deliv Rev 59: 75-86, 2007.

2. Aigner A: Applications of RNA interference: Current state and prospects for siRNA-based strategies in vivo. Appl Microbiol Biotechnol 76: 9-21, 2007.

3. Uprichard SL: The therapeutic potential of RNA interference. FEBS Lett 579: 5996-6007, 2005.

4. Leenders F, Möpert K, Schmiedeknecht A, Santel A, Czauderna F, Aleku M, Penschuck S, Dames S, Sternberger M, Röhl T, et al: PKN3 is required for malignant prostate cell growth downstream of activated PI 3-kinase. EMBO J 23: 3303-3313, 2004. 
5. Aleku M, Schulz P, Keil O, Santel A, Schaeper U, Dieckhoff B, Janke O, Endruschat J, Durieux B, Röder N, et al: Atu027, a liposomal small interfering RNA formulation targeting protein kinase N3, inhibits cancer progression. Cancer Res 68: 9788-9798, 2008.

6. Santel A, Aleku M, Röder N, Möpert K, Durieux B, Janke O, Keil O, Endruschat J, Dames S, Lange C, et al: Atu027 prevents pulmonary metastasis in experimental and spontaneous mouse metastasis models. Clin Cancer Res 16: 5469-5480, 2010.

7. Strumberg D, Schultheis B, Traugott U, Vank C, Santel A, Keil O, Giese K, Kaufmann J and Drevs J: Phase I clinical development of Atu027, a siRNA formulation targeting PKN3 in patients with advanced solid tumors. Int J Clin Pharmacol Ther 50: 76-78, 2012.

8. Taetz S, Bochot A, Surace C, Arpicco S, Renoir JM, Schaefer UF Marsaud V, Kerdine-Roemer S, Lehr CM and Fattal E: Hyaluronic acid-modified DOTAP/DOPE liposomes for the targeted delivery of anti-telomerase siRNA to CD44-expressing lung cancer cells. Oligonucleotides 19: 103-116, 2009.

9. de Wolf HK, Snel CJ, Verbaan FJ, Schiffelers RM, Hennink WE and Storm G: Effect of cationic carriers on the pharmacokinetics and tumor localization of nucleic acids after intravenous administration. Int J Pharm 331: 167-175, 2007.

10. Cardoso AL, Simões S, de Almeida LP, Plesnila N, Pedroso de Lima MC, Wagner E and Culmsee C: Tf-lipoplexes for neuronal siRNA delivery: A promising system to mediate gene silencing in the CNS. J Control Release 132: 113-123, 2008.

11. Hattori Y, Nakamura A, Arai S, Kawano K, Maitani Y and Yonemochi E: siRNA delivery to lung-metastasized tumor by systemic injection with cationic liposomes. J Liposome Res 25: 279-286, 2015

12. Eliyahu H, Servel N, Domb AJ and Barenholz Y:Lipoplex-induced hemagglutination: Potential involvement in intravenous gene delivery. Gene Ther 9: 850-858, 2002.

13. Simberg D, Weisman S, Talmon Y, Faerman A, Shoshani T and Barenholz Y: The role of organ vascularization and lipoplex-serum initial contact in intravenous murine lipofection. J Biol Chem 278: 39858-39865, 2003

14. Hattori Y, Arai S, Kikuchi T, Ozaki K, Kawano K and Yonemochi E: Therapeutic effect for liver-metastasized tumor by sequential intravenous injection of anionic polymer and cationic lipoplex of siRNA. J Drug Target 24: 309-317, 2016.

15. Hattori Y, Arai S, Okamoto R, Hamada M, Kawano K and Yonemochi E: Sequential intravenous injection of anionic polymer and cationic lipoplex of siRNA could effectively deliver siRNA to the liver. Int J Pharm 476: 289-298, 2014.
16. Schmittgen TD and Livak KJ: Analyzing real-time PCR data by the comparative C(T) method. Nat Protoc 3: 1101-1108, 2008.

17. Kato M, Hattori Y, Kubo M and Maitani Y: Collagenase-1 injection improved tumor distribution and gene expression of cationic lipoplex. Int J Pharm 423: 428-434, 2012.

18. Taniguchi Y, Kawano K, Minowa T, Sugino T, Shimojo Y and Maitani Y: Enhanced antitumor efficacy of folate-linked liposomal doxorubicin with TGF- $\beta$ type I receptor inhibitor. Cancer Sci 101: 2207-2213, 2010 .

19. Unsal-Kacmaz K, Ragunathan S, Rosfjord E, Dann S, Upeslacis E, Grillo M, Hernandez R, Mack F and Klippel A: The interaction of PKN3 with RhoC promotes malignant growth. Mol Oncol 6: 284-298, 2012.

20. Palmer RH, Ridden $\mathrm{J}$ and Parker PJ: Cloning and expression patterns of two members of a novel protein-kinase-C-related kinase family. Eur J Biochem 227: 344-351, 1995.

21. Lachmann S, Jevons A, De Rycker M, Casamassima A, Radtke S, Collazos A and Parker PJ: Regulatory domain selectivity in the cell-type specific PKN-dependence of cell migration. PLoS One 6: e21732, 2011.

22. Goel S, Duda DG, Xu L, Munn LL, Boucher Y, Fukumura D and Jain RK: Normalization of the vasculature for treatment of cancer and other diseases. Physiol Rev 91: 1071-1121, 2011.

23. Weis SM and Cheresh DA: Pathophysiological consequences of VEGF-induced vascular permeability. Nature 437: 497-504, 2005.

24. Pinon $\mathrm{P}$ and Wehrle-Haller B: Integrins: Versatile receptors controlling melanocyte adhesion, migration and proliferation. Pigment Cell Melanoma Res 24: 282-294, 2011.

25. Laurent VM, Duperray A, Sundar Rajan V and Verdier C: Atomic force microscopy reveals a role for endothelial cell ICAM-1 expression in bladder cancer cell adherence. PLoS One 9: e98034, 2014.

26. Jimenez D, Roda-Navarro P, Springer TA and Casasnovas JM: Contribution of N-linked glycans to the conformation and function of intercellular adhesion molecules (ICAMs). J Biol Chem 280: 5854-5861, 2005.

27. Mukai H, Muramatsu A, Mashud R, Kubouchi K, Tsujimoto S, Hongu T, Kanaho Y, Tsubaki M, Nishida S, Shioi G, et al: PKN3 is the major regulator of angiogenesis and tumor metastasis in mice. Sci Rep 6: 18979, 2016. 